\title{
TERRITÓRIOS DO CRIME NO ESPAÇO URBANO E MECANISMOS DE PREVENÇÃO
}

\author{
CRIME TERRITORIES IN URBAN SPACE \\ AND PREVENTION MECHANISMS \\ TERRITORIOS DEL CRIMEN EN ESPACIO URBANO \\ Y MECANISMOS DE PREVENCIÓN
}

\section{Márcia Andréia Ferreira Santos}

Doutorado em Geografia pela Universidade Federal de Uberlândia (UFU). Estágio de Doutorado na Universidade do Minho/Portugal (2010).

Av. João Naves de Ávila 2121 - Campus Santa Mônica - Caixa Postal 593 - - CEP 38408-100. Uberlândia - MG. Brasil.

E.mail:marciaufu@yahoo.com.br

\section{RESUMO}

O objetivo deste artigo é apresentar uma discussão acerca do crime violento territorializado em espaços urbanos. Os procedimentos metodológicos basearam-se em levantamento teórico e leitura sobre a temática em livros, dissertações e teses. Após análise das referências selecionadas, constatou-se que o crime violento se estabelece no espaço urbano a partir de elementos que condicionam a sua ocorrência em áreas específicas. O tráfico de drogas, que por sua vez predispõe a incidência de homicídios, é um exemplo. Por esta razão, qualquer estratégia de segurança pública que vise prevenir e/ou controlar as ocorrências criminais no espaço urbano deve considerar que os fatores que condicionam a sua ocorrência são dinâmicos e múltiplos, e não devem ser analisados isoladamente.

Palavras-chave: Território, Crime, Violência, Espaço Urbano, Geografia.

\section{ABSTRACT}

The objective of this paper is to present a discussion of regionalised violent crime in urban areas. The methodological procedures were based on theoretical research and reading on the subject in books, dissertations and theses. After analysis of selected references, it was found that violent crime is established in the urban space from elements that influence their occurrence in specific areas. Drug trafficking, which in turn predisposes the incidence of murders, is an example. For this reason, any public security strategy to prevent and / or control criminal activities in urban areas should consider that the factors that influence their occurrence are dynamic and multiple, and should not be analyzed in isolation.

Keywords: Territory, Crime, Violence, Urban Space, Geography. 


\section{RESUMEN}

El objetivo de este trabajo es presentar un análisis de los delitos violentos regionalizada en las zonas urbanas. Los procedimientos metodológicos se basan en la investigación teórica y leyendo sobre el tema en libros, disertaciones y tesis. Tras el análisis de las referencias seleccionadas, se encontró que el crimen violento se establece en el espacio urbano a partir de elementos que influyen en su aparición en áreas específicas. El tráfico de drogas, que a su vez predispone a la incidencia de asesinatos, es un ejemplo. Por esta razón, cualquier estrategia de seguridad pública para prevenir y / o controlar las actividades delictivas en las zonas urbanas debe considerar que los factores que influyen en su aparición son dinámicas y múltiples, y no debe ser analizado de forma aislada.

Palabras clave: Territorio, Crimen, Violencia, Espacio Urbano, Geografía. 


\title{
O CRIME VIOLENTO NO ESPAÇO URBANO
}

Em se tratando do conceito de espaço urbano, Corrêa (1989, p.7) declara:

\begin{abstract}
O espaço de uma grande cidade capitalista constitui-se, em um primeiro momento de sua apreensão, no conjunto de diferentes usos da terra justapostos entre si. Tais usos definem áreas, como o centro da cidade, local de concentração de atividades comerciais, de serviços e de gestão, áreas industriais, áreas residenciais distintas em termos de forma e conteúdo social, de lazer e, entre outras, aquelas de reserva para futura expansão. Este complexo conjunto de usos da terra é, em realidade, a organização espacial da cidade ou, simplesmente, o espaço urbano, que aparece assim como espaço fragmentado (Destaque do autor).
\end{abstract}

A cidade é o reflexo da sociedade, cuja estrutura reflete a sua forma de organização, estando na sua morfologia impressos os processos cultural, econômico e social de cada momento histórico. Francisco Filho (2004) comenta que

\begin{abstract}
O espaço urbano se apresenta como algo complexo, campo onde as relações humanas se estabelecem e cristalizam nas suas formas e nas relações entre elas. É nesse espelhamento entre as ações e sua dinâmica no território que surge uma geografia do crime, em que cada ação de quebra da ordem e, consequentemente, de um ato de violação dos direitos do cidadão, adquire uma dinâmica e personalidade própria, estabelecendo um conjunto de ações que se interligam a outros fenômenos urbanos, interferindo e moldando a percepção que cada indivíduo passa a ter do espaço onde vive, estabelecendo novas texturas e morfologias no crescimento do tecido urbano, como consequência final de todo o processo (Francisco Filho, 2004, p.27, destaque do autor).
\end{abstract}

Para entender a geografia do crime é necessário compreender a sua dinâmica no espaço e os mecanismos organizacionais utilizados para se estabelecer em lugares específicos do espaço urbano, por vezes fragmentado e, ao mesmo tempo articulado através das relações espaciais que nele se estabelecem (Corrêa, 1989). Como exemplifica Francisco Filho (2004, p.28), os espaços fragmentados podem se segregar e refletir esse processo em usos especializados do solo, onde cada classe ocupa seu território, dando-lhe uma feição própria. Assim, a favelas, que se configuram como espaços desprovidos de “[...] infraestrutura que fornece qualidade de vida mínima aos seus habitantes, representam a ausência do Estado e a vida à margem do processo produtivo a que seus ocupantes estão submetidos”. Por outro lado, os condomínios de luxo são exemplos da segregação que se estabelece numa outra direção desse mesmo fenômeno, onde uma parcela da sociedade, participante do processo produtivo, tem acesso à renda que lhe permite a qualidade de vida, em termos de infraestrutura urbana, melhor do que aquela existente nas favelas.

Conforme Ferreira e Penna (2005), a violência é um fenômeno que se territorializa no espaço urbano por meio de relações sociais que expressam uma configuração geográfica e se estabelecem num momento histórico específico. Essa territorialização da violência se dá a partir da fixação de elementos que possibilitam o estabelecimento de ações capazes de modificar as condições ambientais e sociais, redefinindo o lugar a partir disso. 
As causas da violência, cujas raízes estão arraigadas à produção de espaços excludentes, são multifatoriais e advêm de processos sociais complexos, que por sua vez geram lutas e conflitos socioespaciais ao longo da história. De acordo com as referidas autoras, surgem desse processo desigual, espaços elitizados ocupados pela classe dominante e espaços periféricos constituídos de classes populares sujeitos a toda forma de violência. Periferia urbana aqui entendida como o reduto

[...] de todas as formas de violência, desde a discriminação, ao inacesso aos direitos do cidadão e à própria cidadania [...]. Espaços de exclusão da lei e da ordem social, abrigo da população segregada, reduto da violência em seus diferentes aspectos, são apropriados pelas organizações criminosas elou ilegais que os faz seus espaços de poder. À violência estrutural desses territórios vem-se articular a violência organizada do crime na atualidade. Cria-se, assim, o território da violência, porções do espaço urbano apropriadas pelas organizações criminosas que exercem seu poder sobre eles transformando-os em redutos de poder do crime organizado que daí comanda sua atuação na cidade, enfrenta o estado e manobra o seu exército formado pela população excluída que habita esses locais (Ferreira; Penna, 2005, p.158, destaque nosso).

Origina-se, portanto, um tecido urbano fragmentado, segmentado e contraditório, todavia articulado. Nesse sentido,

Os espaços elitizados das classes dominantes caracterizam-se pelo consumo de bens e de in-
fraestruturas com alto padrão de qualidade e de técnica, financiados pelos governos. Nos es-
paços periféricos predomina a cultura da pobreza e sua dinâmica para reduzir os efeitos de-
vastadores do desemprego (principalmente por intermédio do comércio informal) e das ne-
cessidades habitacionais imediatas. Sem opção no mercado imobiliário, com pouco ou ne-
nhum financiamento público ou privado, predomina a informalidade e a autoconstrução, que
não atende às exigências mínimas de uma habitação normal (Ferreira; Penna, 2005, p.158).

Tal como destacam as autoras supracitadas, os espaços de exclusão existentes na cidade são desvalorizado economicamente devido à morfologia apresentada, tornandose espaços controlados por grupos criminosos, justamente pelo fato de neles já haver a ausência do Estado e de instituições públicas necessárias à manutenção da qualidade de vida e da cidadania. Constata-se, nesse sentido, que a produção do espaço se configura como um processo fragmentador e excludente, cuja

[...] proximidade física no território confronta as diferenças sociais em termos de direitos do indivíduo à sobrevivência, à saúde, ao trabalho, à vida etc. O enclausuramento do pobre, espacialmente próximo das condições da vida moderna urbana e socialmente tão longe dela, fruto do inacesso, ou da periferização, que o torna duplamente distante, dificulta a mobilidade social. Cria-se uma barreira espacial que reproduz a pobreza, como um fator a mais. A pobreza segregada fica mais pobre, tornando mais difícil a mobilidade social e com isso mais vulnerável às ações criminosas (Ferreira; Penna, 2005, p.158).

Como ressaltam as autoras supracitadas, o simples fato de destruir esses espaços ou de transferi-los para outro lugar dentro da cidade não é suficiente, pois “[...] a mesma forma espacial vai aparecer em outro lugar, desde que os processos que lhe deram origem 
persistam". (Ferreira; Penna, 2005, p.159). Outra consequência trazida pelos/aos territórios urbanos controlados pelo crime organizado é o impedimento à mobilidade social das pessoas, criando, assim, novas exclusões. Nesse sentido, como meio de desmobilizar a organização criminosa, faz-se necessário evitar a formação das áreas de risco e tornar menos vulneráveis aquelas já existentes, por meio da gestão do território, com o objetivo de inibir a formação das áreas periferizadas e desvalorizadas, fortalecendo as potencialidades da população local por meio da criação de “[...] oportunidades novas ou estratégicas para que os processos sociais se realizem de forma menos perversa, as mudanças ocorram e os territórios tenham novas identidades”. Ferreira; Penna, 2005, p.167).

À medida que esses territórios são formados e estabelecidos por meio do poder do crime organizado transformam-se em redutos da violência, realimentando, a partir disso, os processos sociais responsáveis pela violência urbana. A população que habita esses espaços torna-se mão de obra absorvida pelo crime que tem, dentre outras atividades ilegais, o tráfico de drogas como mercado de trabalho. É um negócio que vem para ocupar o espaço do trabalho legal, inexistente, escasso e, às vezes, difícil de ser alcançado em algumas cidades. Pelo fato de necessitar de uma elevada quantidade de pessoas para trabalhar em diferentes setores, desempenhando funções específicas e sem exigência de mão de obra qualificada, torna-se uma fonte de renda para muitos desempregados, como também para crianças, cada vez mais incorporadas a esse processo.

Apesar de estar presente em todos os lugares da cidade, a violência apresenta-se em maior ou menor intensidade em determinados locais, e é isso que vai definir como as pessoas sentem tal fenômeno. Uma das principais formas de sentir a violência é através da sensação de insegurança e medo que imperam em maior ou menor grau, de acordo com o local habitado. A violência apresenta uma dinâmica própria no espaço, sendo capaz de moldar os lugares e o comportamento das pessoas. Ela estabelece "[...] um conjunto de ações que se interligam a outros fenômenos urbanos, interferindo e moldando a percepção que cada indivíduo passa a ter do espaço onde vive, estabelecendo novas texturas e morfologias no crescimento do tecido urbano". (Francisco Filho, 2004, p. 27).

A Geografia tem se preocupado com o estudo da violência, sobretudo devido aos impactos proporcionados por ela ao espaço e à cotidianidade da população. Queiroz (2002, p. 98) declara que "A violência que atinge as cidades brasileiras deixou de ser um fenômeno localizado e ganhou status de problema nacional". As pessoas não se conhecem e pouco se comunicam. Isolaram-se nos condomínios fechados, nos apartamentos, nas casas repletas de sistema de segurança, fatores estes que nem sempre são eficazes. A criminalidade violenta, dessa forma, atua diretamente no cotidiano das cidades, regulando o modo de vida 
e o comportamento das pessoas e segregando as populações quer por escolha deliberada ou por imposição socioeconômica.

Pelo fato de transformar e reorganizar o espaço, a violência é utilizada como elemento de especulação imobiliária pelas construtoras. Muitos empreendedores imobiliários, quando planejam os condomínios horizontais e verticais, utilizam em suas propagandas discursos que valorizam a plena segurança do local contra atos violentos. Atualmente, nem mesmo as estratégias de monitoramento das residências por meio de câmeras de vigilância, ou ainda a utilização de cercas elétricas, muros altos, cães e vigilantes têm sido suficientes para conter o avanço da violência. Mas, ainda que insuficientes, inibem a atuação de criminosos, pois dificultam sua ação.

Tanto a fala quanto o medo da criminalidade violenta “[...] organizam as estratégias cotidianas de proteção e reação que tolhem os movimentos das pessoas e restringem seus universos de interações". (Caldeira, 2000, p.27). Com isso, “[...] percebe-se que vários tipos de interação espacial diminuem (e até tendem a desaparecer) ou tornar-se (muito) mais seletivos". (Souza, 2008, p.58, destaque do autor). Dessa forma, criam-se “[...] novas alternativas de sociabilidade, alterando o modo de ser e de agir das pessoas”. (Baierl, 2004, p.22).

Como ressalta Carpaneda (2008, p.17), “A segurança expressa no desenho urbano, ou nas edificações, sempre esteve presente ao longo da história”. Os exemplos disso são claros, ao se observar as muralhas, fortificações e fossos dos castelos, erigidos com o objetivo de proteger o espaço contra inimigos. Essa busca histórica por proteção tem se revelado, nos dias atuais, como um elemento vital, e, para muitos habitantes das grandes cidades, um fator essencial para a vida. Hoje, o medo da violência ligado à elevação da insegurança urbana tem influenciado, de igual modo, a modelagem de formas de moradia e habitat, o que pode ser percebido com o surgimento dos condomínios fechados, tomados como mecanismos que favorecem a manutenção da segurança. Tais edificações urbanas recebem nomes diferentes em diversas cidades do mundo: em Buenos Aires, chamam-se barrios cerrados ou countries; em Joanesburgo, walled communities e security villages; no Brasil, condomínios exclusivos ou fechados (Souza, 2008). Para Debord (1997), são considerados pseudocampesinatos.

Conforme afirmação de Debord (1997), os pseudocampesinatos surgem de modificações espaciais e sociais trazidas pelo urbanismo que destrói as cidades e reconstitui os condomínios fechados nos quais

[...] estão perdidas tanto as relações naturais do antigo campo quanto as relações sociais diretas e diretamente questionadas, da cidade histórica. Um novo campesinato artificial é recriado pelas condições de habitat e de controle espetacular no atual 'território planificado': a dispersão no espaço e a mentalidade estreita, que sempre impediram o campesinato de empreender uma ação independente e de se afirmar como força histórica criadora, voltam 
a ser as características dos produtores. [...] 'As cidades novas' do pseudocampesinato tecnológico fixam no terreno, claramente, a ruptura com o tempo histórico no qual elas são construídas; sua divisa pode ser: 'Aqui, nunca acontecerá nada, e 'nada nunca aconteceu' (Debord, 1997, p.117).

Souza (2008, p.54) ressalta que

[...] se nem shopping centers e nem mesmo bancos ou "condomínios exclusivos", com todo o seu aparato de segurança, são completamente seguros; se prédios de apartamentos da classe média alta são invadidos e saqueados com frequência; se sequestros "comuns" e sequestros relâmpago se tornam corriqueiros; se basta ser tido por "suspeito", pela aparência, para ser discriminado, humilhado e, no limite, executado por policiais agindo como justiceiros ou em retaliação; então, onde, afinal, estariam os "lugares seguros"? (Destaque do autor).

Tais condomínios podem ser caracterizados como construções que “[...] ameaçam o fortalecimento de valores de civilidade e solidariedade cidadã, uma vez que são ambientes de socialização que, a um só tempo, pressupõem e reforçam um descompromisso para com a cidade como um todo" (Souza, 2008, p.74). O fato de um indivíduo isolar-se da cidade indo morar num condomínio fechado leva a entender que ele está "fugindo" das "ameaças" existentes nos demais espaços da cidade e, por conseguinte, eximindo-se das responsabilidades que ele, como habitante de determinado local, tem sobre a manutenção da segurança, já que isso não cabe apenas ao poder público, mas a todos os cidadãos. Essas edificações reforçam exclusões e autoexclusões, rompendo com a unidade social, "[...] que provém de uma atividade cotidiana de um agir comunicacional". (Gomes, 2002, p.161). Esse processo de fuga é, acima de tudo, do contato com o "mundo extramuros"; é, especialmente, um ausentar-se do espaço público, caracterizado como “[...] um lugar de conflitos, de problematização da vida social, mas, sobretudo é o terreno onde esses problemas são assinalados e significados". (Gomes, 2002, p. 164). Acrescenta-se que

[...] o arranjo físico das coisas é um agente ativo na realização de determinadas ações sociais, e essa ordem espacial é concebida como uma condição para que essas ações se produzam. Isso quer dizer que as práticas sociais são, em certa medida, dependentes de uma dada distribuição ou arrumação das coisas no espaço (Gomes, 2002, p.172).

Nos condomínios fechados,

Os limites com o mundo externo são bem demarcados, e o controle e a vigilância são elementos fundamentais em seu funcionamento [...]. As mensagens publicitárias para a venda desses imóveis exploram bastante a ideia de um ambiente planejado que produzirá toda a qualidade de vida do ambiente urbano, com a vantagem da segurança e da homogeneidade social (Gomes, 2002, p.186).

Diz-se homogeneidade social, pois nem todos os cidadãos dispõem de condições financeiras que possibilitem habitar em tais empreendimentos. O que se quer ressaltar aqui é que a violência está em todos os lugares, inclusive nos condomínios e/ou loteamentos 
fechados; talvez em menor quantidade, mas a verdade é que o fato de se refugiar em tais empreendimentos não soluciona o problema da vitimização. Esses espaços são, portanto, considerados pelo referido autor como "ilhas utópicas".

Moura (2008), que analisou a estruturação dos condomínios horizontais e loteamentos fechados em Uberlândia-MG, identificou que 42 desses empreendimentos foram formados e vendidos sob a égide do tema da segurança, presente nas propagandas divulgadas. Dentre os serviços de segurança oferecidos estavam: cercas elétricas em toda a extensão do condomínio, portaria 24 horas, câmeras de vigilância e ronda. Tais elementos são os diferenciais apresentados pelas construtoras para atrair o comprador. Além destes, a existência de muros altos no entorno da área do condomínio horizontal/loteamentos configura-se como "[...] símbolos de defesa territorial e uma forma de isolamento social, ou seja, isolamento dos problemas externos". (Moura, 2008, p.132). Exemplos desses elementos espaciais podem ser verificados nas Figuras 1 e 2:

Figura 1.Cidade de Uberlândia: Folheto de propaganda divulgando os equipamentos de segurança existentes no Paradiso Condomínio Ecológico - 2007.

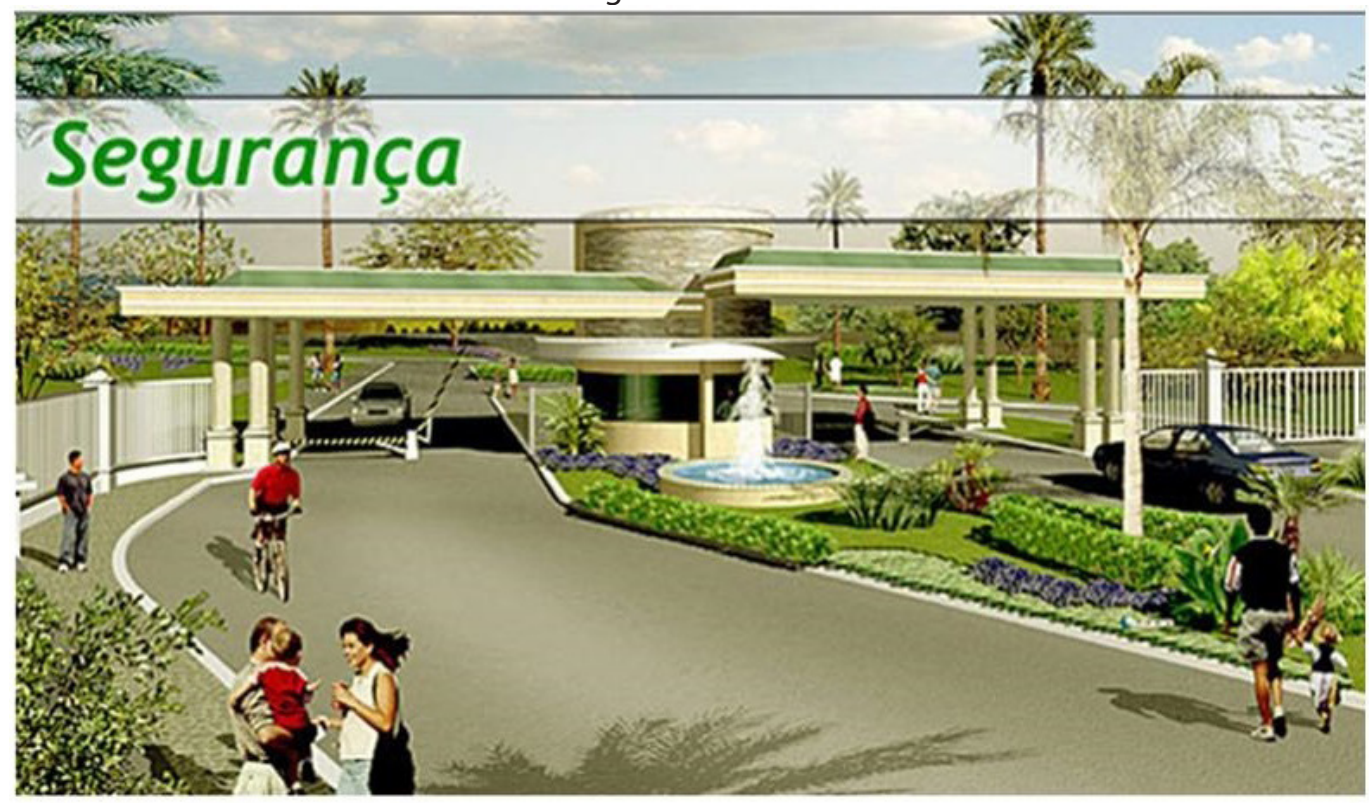

- Condominio Fechado horizontal

- Cerca Elétrica em toda extensão

- Portaria 24 horas

- Câmeras de vigilância

- Ronda a cavalo.

- Mais segurança e liberdade.
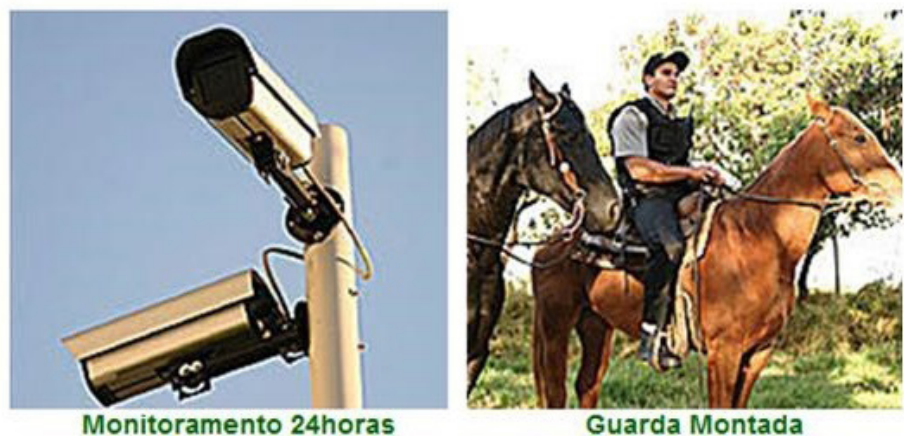

Fonte: Moura (2008) 
Figura 2. Cidade de Uberlândia: Muros altos circundando os loteamentos fechados Jardins Barcelona, Vila dos Ipês e Bosque Karaíba, respectivamente - 2007.

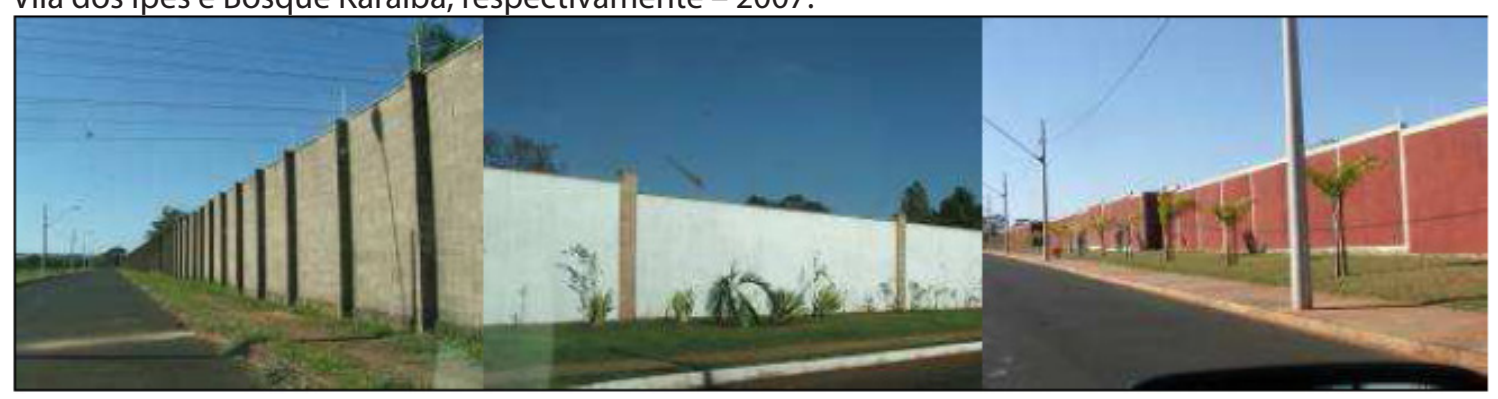

Fonte: Moura (2008, p.132).

Observa-se, portanto, que a criminalidade violenta altera a forma do espaço, bem como a maneira pela qual os habitantes da cidade lidam com tais modificações. Até mesmo o espaço público se altera sendo, muitas vezes, ou abandonado ou apropriado de forma indevida, através da privatização ou da vigilância:

A rua, antes acessível por todos, hoje tem se transformado num espaço restrito, onde a livre circulação é impedida por altos muros vigiados por seguranças desconfiados diante de qualquer movimento suspeito, com regras próprias e com câmeras de segurança instaladas a uma distância considerável dos condomínios [...], como uma forma de vigiar todos que se aproximam dele. Sair fora dos muros significa ficar exposto à marginalidade da cidade (Moura, 2008, p.132-133).

Acerca da privatização dos espaços públicos, Pedrazzini (2006) declara que:

[...] os espaços públicos tendem à privatização para atender às exigências de segurança $\mathrm{e}$ com o consentimento dessa mesma maioria de habitantes privatizados de seus direitos fundamentais de cidadãos e cuja qualidade de vida encontra-se deteriorada. A privatização do espaço público equivale à sua destruição [...]. O método de privatização é simples e eficaz: em primeiro lugar, a cidade é declarada nociva e perigosa, seus espaços públicos tradicionais devem ser, portanto, evitados e demolidos [e ironicamente] surgem assim novos espaços públicos seguros, os shopping centers, onde o público não corre o mínimo risco de agressão (Pedrazzini, 2006, p.118).

Pedrazzini (2006, p.119), citando Davis (1997) declara que com a insegurança reinando nas cidades, “[...] as ruas perdem suas perspectivas e a circulação desloca-se para corredores vigiados por seguranças privados". Além disso,

Com a atuação conjugada dos poderes públicos e dos atores privados a cidade se recompõe num movimento de grande violência simbólica, "fechando os lugares públicos e levando o público para locais onde estará duplamente seguro: não correrá risco nem será suspeito” [dito irônico] (Pedrazzini, 2006, p.119).

Carvalho (2008) declara que Praia Grande foi a primeira cidade do Brasil a possuir uma Central de Videomonitoramento, interligada à Guarda Municipal e à Polícia Militar. Em 2002, 
foram instaladas 1200 câmeras de vídeo ao longo dos locais de maior movimento da cidade, bem como em prédios públicos e monumentos. Em 2012, a cidade já possuía 1530 câmeras (Flosi, 2012). Após a utilização dessa tecnologia, os índices de criminalidade caíram cerca de 60\%, e as depredações de equipamentos públicos municipais, em 40\%. De acordo com o referido ator, Praia Grande é a cidade com a maior quantidade de câmeras de vigilância das Américas, e a segunda do mundo, vindo após a cidade de Londres, na Grã-Bretanha. Este sistema, segundo Carvalho (2008), foi instalado em outras cidades brasileiras, como SuzanoSP, Sobral-CE, Olinda-PE, Joinville-SC e Curitiba-PR, em parceria com a Polícia Militar e/ou a Guarda Municipal. Após a instalação destes equipamentos, todas as cidades supracitadas apresentaram uma considerável diminuição dos índices de criminalidade no local.

Outra consequência trazida pela violência é a estigmatização de alguns espaços urbanos, que assumem uma dimensão altamente expressiva da vida cotidiana, afetando negativamente as oportunidades nos círculos sociais, nas escolas e nos mercados de trabalho. Geralmente, as áreas mais violentas "[...] tendem a ser evitadas pelos de fora, 'assinaladas' pelos bancos e corretores de imóveis, desdenhadas pelas firmas comerciais e ignorados pelos políticos". (Wacquant, 2005, p. 33). Essa estigmatização territorial, conforme o referido autor, dá origem entre os moradores a estratégias de evasão e distanciamento mútuos, e exacerba processos de diferenciação social interna, que tendem a diminuir a confiança interpessoal e o senso de coletividade fundamental para a ação coletiva. Bourdieu (2003, p. 166) acrescenta que“[...] o bairro estigmatizado degrada simbolicamente os que o habitam, e que, em troca, o degradam simbolicamente, porquanto estando privados de todos os trunfos necessários para participar dos diferentes jogos sociais, eles não têm em comum senão sua excomunhão".

Acerca da estigmatização territorial, Esteves (1999) constatou em seu estudo sobre a criminalidade violenta em Lisboa que $44,7 \%$ dos entrevistados por ela afirmaram evitar lugares onde existem barracas, espécie de habitação utilizada por pessoas de baixa renda. Conforme os entrevistados, a razão de se evitar circular por estes locais relaciona-se ao medo difuso da violência, marcado, sobretudo, pelas notícias divulgadas através dos meios de comunicação social sobre estas áreas, consideradas espaços de miséria e de degradação social e material, ou através de conversas estabelecidas com amigos e familiares sobre delitos praticados no local, em que as vítimas geralmente são estranhas aos moradores do bairro.

\section{PREVENÇÃO DA CRIMINALIDADE VIOLENTA}

Por muito tempo, o controle da criminalidade violenta foi realizado apenas por meio da punição dos infratores. Em 2002, a OMS publicou o Relatório Mundial sobre Violência e 
Saúde com discussões acerca da necessidade de mudar o paradigma da repressão e punição como única forma de se enfrentar a violência, optando-se pela prevenção (Krug et al., 2002). Mas desde décadas anteriores diversos autores já vinham apresentando as estratégias de prevenção como uma forma mais eficaz de controle da criminalidade violenta.

Silveira (2007) declara que a prevenção enquanto conceito aplicado a políticas públicas surgiu de forma sistemática no campo da saúde, na década de 1950 com teorizações clássicas desenvolvidas por Leavel e Clark (1958), segundo as quais é possível antecipar ou tornar impossível, por meio da aplicação de intervenções precoces, o desenvolvimento de doenças e agravos à saúde.

Conforme a referida autora, tais intervenções fundamentam-se

[...] na interrupção de uma cadeia de eventos na qual se busca neutralizar, eliminar ou minimizar os agentes causais (fatores de risco), ou interferir nos mecanismos que levam ao agravo. Portanto, elemento fundamental à ideia de prevenção é a possibilidade de identificar fatores de risco ou mecanismos causais, e fatores de proteção sem os quais a operacionalização de qualquer medida antecipatória constituiria um experimento às cegas (Silveira, 2007, p.60).

Aplicada ao problema da criminalidade, as medidas de prevenção seriam “[...] ações proativas informadas por uma teoria sobre a gênese do crime, ou pelo conhecimento empírico dos fatores que se associam de forma mediata e imediata com as ações criminosas ou violentas, em determinado tempo, e local". (Silveira, 2007, p.60). Citando Leavell e Clark (1958), a autora fala de três níveis de prevenção: primária, secundária e terciária, e que os mesmos podem ser adaptados ao problema do crime.

A prevenção primária incorpora abordagens que abrandam as causas do crime por meio de medidas direcionadas a toda a população. As intervenções geradas neste nível são realizadas no meio ambiente físico e social no sentido de reduzir os fatores de risco e aumentar os de proteção com o objetivo de minimizar as oportunidades do crime, dificultando a ação criminal e reduzindo o lucro dos criminosos. Neste plano, tal como afirma Silveira (2007), são estabelecidas estratégias educacionais como o reforço à consciência jurídica, no caso da fidelidade à norma, e são atacadas as causas da criminalidade no nível da socialização e das carências estruturais. Tais medidas não são de competência apenas das agências públicas de segurança, mas da sociedade como um todo e de outras instituições como a escola e a família.

A prevenção secundária tem por objetivo reduzir os fatores sociais e econômicos que propiciam a ocorrência de ações criminosas, dirigindo-se aos grupos de risco caracterizados como potenciais agressores ou vítimas devido ao grupo etário, local de moradia, estilo de vida, condição socioeconômica e outros fatores que os particularizam. Como exemplos de 
medidas desse tipo de prevenção, citam-se: 1) Programas de treinamento de segurança para idosos; 2) Programas nos quais os moradores organizam grupos de vigilância da vizinhança; 3) Projetos que visam interferir em comportamentos problemáticos de grupos de jovens antes que os mesmos conduzam a comportamentos criminosos; 4) Projetos e programas que busquem garantir suporte social a jovens que vivem em áreas de risco.

A prevenção terciária é constituída de ações de longo prazo voltadas à reabilitação e reintegração de vítimas e agressores, ao estabelecimento de suporte às vítimas e suas famílias, à compensação e reparação de danos causados pela violência, e desenvolve programas que visam evitar a reincidência e a prevenir a vitimização. Portanto, a abordagem da prevenção da violência deve levar em consideração estes três níveis apresentados, ou seja,

[...] o cumprimento da lei - isto é, garantir a manutenção da ordem nas atividades cotidianas da comunidade e reduzir o medo da população com relação ao crime - com a prevenção social - isto é, programas envolvendo diversos organismos que enfrentem as causas do crime e da violência - e com prevenção 'situacional' - isto é, medidas para reduzir as oportunidades (Banco Mundial, 2003, p.13).

Para se estabelecer estratégias de prevenção à violência é imprescindível que se saibam quais grupos ou indivíduos são prioritários na atuação, escolhendo, dessa forma, as melhores estratégias de ação. Minayo e Souza (1999) destacam que no caso brasileiro, os problemas que mais afligem a população referem-se ao elevado crescimento do crime organizado nos grandes centros urbanos, do contrabando de armas de fogo, aumento da delinquência juvenil e dos crimes contra as pessoas, o patrimônio e a impunidade dos criminosos. $\mathrm{O}$ narcotráfico repercute em outras formas de delinquência, como assaltos a bancos, roubos de carros, de cargas, sequestros e outras formas de violência geral e difusa. Neste sentido, as ações primárias devem voltar-se para o estabelecimento de estratégias que possam impedir o enraizamento dos fatores que predispõem o aparecimento desses elementos.

Silveira (2007, p. 78) destaca que os programas de prevenção ao crime e à violência ainda são raros no Brasil, e sua implementação encontra as seguintes dificuldades: 1) Precariedade dos sistemas de informação em segurança pública, com dados de qualidade questionável, além da falta de informações importantes, como de armas utilizadas, características de agressores e vítimas, circunstâncias dos eventos; 2) Falta de diagnósticos sociodemográficos e cultural sistematizados e detalhados, bem como do perfil de organização da criminalidade das áreas que concentram maior número de eventos; 3) Inexperiência em programas de prevenção em segurança pública; 4) Escassez de profissionais especialistas em crime, e técnicos que realizem diagnósticos, implementação, monitoramento e avaliação de programas desta natureza; 6) Concentração de eventos criminosos como os homicídios em áreas de grande vulnerabilidade social, cujas populações apresentam baixa capacidade 
de mobilização e organização para demandar soluções no plano das políticas públicas destinadas ao problema; 7) Resistência à integração entre as agências de justiça criminal e ao planejamento e implementação articulada de ações de prevenção; 8) Grande pressão por destinação de recursos para políticas tradicionais de caráter apenas repressivo; 9) Falta de políticas de financiamento adequadas.

A prevenção da criminalidade e da violência é uma ação prioritária do governo brasileiro, presente na Política Nacional de Redução da Morbimortalidade por Acidentes e Violências. Nela “[...] estão contempladas e valorizadas medidas inerentes à promoção da saúde e à prevenção desses eventos, mediante o estabelecimento de processos de articulação com diferentes segmentos sociais". (Brasil, 2001, p. 2). A proposta dessa portaria prevê diretrizes que promovam a adoção de comportamentos e ambientes seguros e saudáveis, por meio da

[...] ampla mobilização da sociedade em geral, e da mídia em particular, para a importância dos acidentes e das violências, bem como o reforço das ações intersetoriais relacionadas ao tema. [...] A co-responsabilidade do cidadão num sentido amplo, incluindo a participação na reivindicação, nas proposições e no acompanhamento desta Política, e na promoção de ambientes seguros e comportamentos saudáveis relacionados à prevenção de acidentes e de violências e de seus fatores de risco, como uso de drogas e álcool, armas de fogo, a não observância de regras de segurança e as relações interpessoais conflituosas. As medidas nesse sentido considerarão tanto os ambientes domésticos, de lazer, de trabalho e de trânsito, quanto aqueles em que se desenvolvem os processos de convivência social. (Brasil, 2001, p. 13).

O que tem sido observado sobre a prevenção do crime é que se tem enfatizado apenas o controle, sendo, portanto, uma reação à infração ou uma medida tomada após a ocorrência do delito. É, portanto, uma resposta ao comportamento infracional, tendo como elemento preventivo a suposição de que a medida de punição tomada é capaz de deter e controlar comportamentos futuros que violem a lei. Por outro lado, Silveira (2007, p. 63-64) destaca que prevenção são medidas que tem por finalidade evitar a ocorrência do crime. Assim, "A sobreposição entre controle e prevenção ocorre quando um crime acontece e a resposta da sociedade é focada na inibição da ocorrência de novos crimes por parte de um mesmo indivíduo particular”. Dessa forma, a prevenção pressupõe que a tomada de determinadas medidas evita a ocorrência de situações indesejadas. Por esta razão, ela é de caráter próativo, cujas medidas devem ser adotadas antes que o crime ocorra. O controle, por sua vez, é reativo e se dá após o acontecimento do crime.

Sherman e outros (1997) realizaram uma avaliação dos programas de prevenção da criminalidade nos Estados Unidos, e concluíram que as medidas devem levar em consideração as seguintes questões: a) Redução da criminalidade juvenil, atividade de gangues de jovens, abuso, e outros fatores de alto risco; (b) Reduções nos fatores de risco 
nos ambientes comunitários, escolas e família que contribuem para a violência juvenil; e (c) Aumento da proteção contra fatores que aumentam a probabilidade de estabelecimento de comportamento criminoso. Rolim (2006) ressalta que o discurso sobre a prevenção da criminalidade e da violência no Brasil sempre se direciona à necessidade de aperfeiçoamento das políticas sociais, com destaque para a distribuição de renda, geração de trabalho, qualidade dos serviços destinados à educação, saúde, moradia, transporte público, lazer.

Welsh (2005) ressalta que são diversas as estratégias de controle da violência. Mas entre as opções existentes, deve-se dar ênfase em como enfrentar as carências econômicas e sociais que podem predispor à ocorrência da violência. Ele afirma que pesquisas recentes apontam para várias dimensões da pobreza que estão relacionadas a altas taxas de violência: elevada concentração de pobreza, transitoriedade da população, ruptura familiar, congestionamento da habitação, fraqueza na estrutura social local (por exemplo, uma baixa participação organizacional da vida na comunidade, fracos laços intergeracionais nas famílias e comunidades, e baixa densidade de amigos e conhecidos), e da presença de mercadorias perigosas ou oportunidades associadas à violência (por exemplo, a disponibilidade de armas e redes de distribuição de drogas). O referido autor acrescenta que para que os programas de prevenção da violência sejam eficazes esses fatores sociais e econômicos fundamentais devem ser abordados. Nesse sentido, Cerqueira e Lobão (2003) também defendem que as políticas públicas voltadas à prevenção da violência devem partir da conjugação de políticas sociais (estruturais ou compensatórias) e políticas relacionadas ao sistema de justiça criminal

Cerqueira e Lobão (2003) comentam que o planejamento com vistas ao estabelecimento de estratégias de prevenção à violência deve partir, primeiramente, do desenvolvimento de modelos e metodologias para analisar os determinantes da criminalidade. Posteriormente, devem-se realizar estudos que levem em conta as informações individuais dos grupos que ocasionam a violência. Por fim, faz-se necessário estudar os determinantes da dinâmica criminal em particular. De acordo com os referidos autores, num segundo momento este projeto de prevenção estende-se para o estudo dos custos e consequências da criminalidade e a junção dos dois eixos para a análise de custo-benefício de programas de segurança pública.

\section{CONSIDERAÇÕES FINAIS}

Pelo fato de a criminalidade violenta apresentar um caráter multifacetado, Cerqueira e Lobão (2003, p.1) ressaltam que o planejador público não deve utilizar apenas um modelo teórico para compreender a determinação do crime violento e a partir disso tomar a 
suas decisões e orientar suas ações e recursos. Daí advém a necessidade de empreender um trabalho multidisciplinar que permita aumentar o conjunto de instrumentos de análise para um fenômeno complexo como a violência. Além disso, do ponto de vista da intervenção pública, com vistas à manutenção da paz social, faz-se necessário verificar se em determinada região há alguma regularidade estatística acerca dos fatores criminogênicos, como: presença de armas e drogas, supervisão familiar e se o Estado dispõe de instrumentos para intervir nessa realidade, sobretudo com a participação da própria sociedade.

Não que o conhecimento das causas seja menos importante, mas compreender a manifestação da criminalidade violenta e as modificações condicionadas por ela no espaço e no modo de vida das pessoas torna-se uma questão fundamental, sobretudo para se estabelecer, a partir disso, intervenções sobre os fatores que a predispõem. A partir de sua manifestação espacial é possível estudar e verificar quais são os principais fatores motivadores para sua atuação. Então, é necessário, primeiramente, que a violência se manifeste no espaço para, posteriormente, estudá-la e compreendê-la? De modo algum, mas este pode ser o caminho, já que se trata de um fenômeno sobremaneira complexo, mas que sua concretude se apresenta como um ponto crucial para a sua interpretação.

É importante, também, ressaltar que alguns fatores espaciais, sociais, culturais ou econômicos atuam como elementos de incidência, e outros de prevalência dos atos violentos num dado lugar. Daí a necessidade de se conhecer a forma tal como a violência se manifesta no espaço para se verificar em que circunstâncias e quais elementos contribuem para que haja um elevado número de casos de um determinado crime naquele local, e por que há uma prevalência dos mesmos ali, ainda que projetos de intervenção tenham sido executados com a finalidade de minimizar tais casos.

\section{REFERÊNCIAS}

1. BAIERL, Luzia Fátima. Medo social: Da violência visível ao invisível da violência. São Paulo: Cortez, 2004. 224p.

2. BANCO MUNDIAL. Prevenção comunitária do crime e da violência em áreas urbanas da América Latina: um guia de recursos para municípios. São Paulo: Banco Mundial, 2003. 80p.

3. BOURDIEU, Pierre. A miséria do mundo. Petrópolis, RJ: Vozes, 2003.

4. BRASIL. Portaria GM/MS n 737, de 16 de maio de 2001, Publicada no DOU No 96 Seção 1e - de 18 de maio de 2001. Política Nacional de Redução da Morbimortalidade por Acidentes e Violências. Brasília, DF: 2001. 
5. CALDEIRA, Tereza Pires do Rio. Cidade de muros: crime, segregação e cidadania em São Paulo. São Paulo: Editora 34/EDUSP, 2003. 399 p.

6. CARPANEDA, Luciana Viana. Contribuições para o desenho de espaços urbanos seguros: um estudo de caso nas Superquadras do Plano Piloto de Brasília. 2008. 143f. Dissertação (Mestrado em Arquitetura) - Faculdade de Arquitetura e Urbanismo, Brasília, 2008.

7. CARVAlHO, Ederson de Assis. Projeto Olho Vivo: "A Iris dos Olhos da Segurança Pública" - Uma análise Geográfica. 2008. 100f. Dissertação (Mestrado em Geografia) - Departamento de Geografia, Pontifícia Universidade Católica de Minas Gerais, Belo Horizonte, 2008.

8. CERQUEIRA, Daniel; LOBÃO, Waldir Lobão. Determinantes da criminalidade: uma resenha dos modelos teóricos e resultados empíricos. Rio de Janeiro: IPEA, 2003. ISSN 1415-4765.

9. CORRÊA, Roberto Lobato. O espaço urbano. São Paulo: Ática, 1989. 75p.

10. DEBORD, Guy. A sociedade do espetáculo. Tradução de Estela dos Santos Abreu. Rio de Janeiro: Contraponto, 1997. 238p.

11. ESTEVES, Alina Isabel Pereira. A criminalidade na cidade de Lisboa: a geografia da insegurança. Lisboa: Edições Colibri, 1999. 214p.

12. FERREIRA, Ignez Costa Barbosa; PENNA, Nelba Azevedo. Território da violência: um olhar geográfico sobre a violência urbana. Revista GEOUSP - Espaço e Tempo, São Paulo, n.18, p.155-168, 2005.

13. FLOSI, Lorena. Videomonitoramento é destaque no noticiário nacional, PG Notícias, (Departamento de Comunicação Social), 05 jan. 2012. Disponível em: <http://www.praiagrande. sp.gov.br/pgnoticias/noticias/noticia_01.asp?cod=23905\&cd_categoria=>. Acesso em: 11 fev. 2012.

14. FRANCISCO FILHO, Lauro Luiz. Distribuição espacial da violência em Campinas: uma análise por geoprocessamento. 2004. 170 f. Tese (Doutorado em Geografia) - Instituto de Geociências - Departamento de Geografia, Universidade Federal do Rio de Janeiro, Rio de Janeiro, 2004.

15. FRIDAY, P.C. Crime and Crime Prevention in China. Journal of Contemporary Criminal Justic,p. 296-314, 1998.

16. GOMES, Paulo César da Costa. A condição urbana: ensaios de geopolítica da cidade. Rio de Janeiro: Bertrand Brasil, 2002. 304p.

17. KRUG, Etienne G. et al. Relatório mundial sobre violência e saúde. Genebra: OMS, 2002. 380p. ISBN 9241545615.

18. LEAVELLL, H; CLARK, E. G. Preventive Medicine for the doctor in his community. New York: McGraw-Hill, 1958.

19. MINAYO, Maria Cecília de Souza; SOUZA, Edinilsa Ramos de. É possível prevenir a violência? Reflexões a partir do campo da saúde pública. Ciência \& Saúde Coletiva, v.4, n.1, p.7-32, 1999.

20. MOURA, Gerusa Gonçalves. Condomínios horizontais/loteamentos fechados e a vizinhança (in)desejada: um estudo em Uberlândia/MG. 2008. 270f. Tese (Doutorado em Geografia) Instituto de Geografia, Universidade Federal de Uberlândia, Uberlândia, 2008. 
21. PEDRAZZINI, Yves. A violência das cidades. Petrópoles, RJ: Vozes, 2006. 188p.

22. QUEIROZ, L. da S. A cidade sitiada: da violência consentida ao medo com sentido. In: PONTUCHKA, N. N.; OLIVEIRA, A. V. (org.). Geografia em Perspectiva, São Paulo: Contexto, 2002.p. 97-106.

23. SHERMAN, Lawrence W. etal.Preventing Crime: What works, what doesn't, what's promising. 1997.

24. SILVEIRA, Andréa Maria. Prevenindo homicídios: avaliação do Programa Fica Vivo no Morro das Pedras em Belo Horizonte. 2007. 290f. Tese (Doutorado em Sociologia) - Faculdade de Filosofia e Ciências Humanas, Universidade Federal de Minas Gerais, Belo Horizonte, 2007.

25. SOUZA, Marcelo José Lopes de. O desafio metropolitano:um estudo sobre a problemática sócio-espacial nas metrópoles brasileiras. Rio de Janeiro: Bertrand Brasil, 2000. 368p.]

26. WELSH, B.C. Public health and prevention of juvenile criminal violence. Youth Violence and Juvenile Justice, v. 3, n. 1, p. 23-40, 2005.

Artigo recebido em 12 de novembro de 2015.

Artigo aceito em 9 de dezembro de 2015. 